\title{
Quantification of Juvenile Hormone III in the Sedge Cyperus iria L.: Comparison of HPLC and Radioimmunoassay
}

\author{
J. C. Bede, ${ }^{1}$ W. G. Goodman ${ }^{2}$ and S. S. Tobe ${ }^{1 *}$ \\ ${ }^{1}$ Department of Zoology, University of Toronto, Ontario, Canada \\ ${ }^{2}$ Department of Entomology, University of Wisconsin, Madison, WI, USA
}

\begin{abstract}
Juvenile hormone III (JH III), a sesquiterpenoid involved in the regulation of insect development and reproduction, appears to be ubiquitous in insects and has also been isolated from some species of sedge. The quantification of JH III extracted from the sedge Cyperus iria by HPLC and by radioimmunoassay (RIA) has been compared. The RIA, developed originally to determine insect haemolymph titres, was optimized for the analysis of plant tissues. The antiserum 31867 displayed minimal cross-reactivity with precursors of JH III from the insect biosynthetic pathway or with extracts from related plant species. Analysis of standards and plant extracts by HPLC and RIA confirmed that there was no significant difference between the ability of these two techniques to quantify JH III (paired $t$-test). Therefore, RIA was subsequently used to determine the distribution of JH III in mature plants of $C$. iria. Substantial concentrations were detected in the above-ground plant tissues $(0.2-1.2 \mu \mathrm{g} / \mathrm{g}$ fresh weight), but the majority of JH III was found in the roots $(43.5 \mu \mathrm{g} / \mathrm{g}$ fresh weight). Copyright (C) 2000 John Wiley \& Sons, Ltd.
\end{abstract}

Keywords: juvenile hormone III; radioimmunoassay; high performance liquid chromatography; Cyperus iria.

\section{INTRODUCTION}

Insect juvenile hormones (JHs) are sesquiterpenoids involved in the regulation of physiological processes associated with metamorphosis and reproductive maturation (Wigglesworth, 1985; Gilbert et al., 1996). To date, six naturally occurring JHs have been identified; they share a common sesquiterpenoid backbone, a methyl ester on $\mathrm{C}-1$ and an epoxide function between $\mathrm{C}-10$ and C-11. Of these compounds, JH III (methyl-10R,11epoxy-3,7,11-trimethyl-2E,6E-dodecadienoate; Fig. 1) appears to be ubiquitous and has been isolated from many insect orders including Lepidoptera (moths and butterflies), Coleoptera (beetles), Hymenoptera (sawflies, wasps, ants and bees), Orthoptera (grasshoppers, locusts, katydids and crickets), Dictyoptera (cockroaches) and Isoptera (termites) (Schooley, 1977; Tobe and Feyereisen, 1983). In most of these orders, JH III is the only juvenile hormone present.

One defensive strategy of plants against insect herbivory is the production of secondary metabolites which interfere with insect physiological functions (Rosenthal and Berenbaum, 1991 and references therein). Some plant compounds have been shown to mimic $\mathrm{JH}$ activity or to inhibit their biosynthesis (for a review see Bede and Tobe, 1999). However, Toong et al. (1988) isolated JH III and its biosynthetic precursor in insects, namely methyl-(2E,6E)-farnesoate (Fig. 1), from

\footnotetext{
* Correspondence to: S. S. Tobe, Department of Zoology, University of Toronto, Ontario, Canada M5S 3G5.

E-mail: stephen.tobe@utoronto.ca

Contract/grant sponsor: Natural Sciences and Engineering Research Council of Canada.
}

the sedges Cyperus iria L. and C. aromaticus (Ridley) Mattf and Kük. This was the first example, and remains the only one to date, of the extraction and identification of a JH from a plant. The level of JH III was reported to be $151 \mu \mathrm{g} / \mathrm{g}$ fresh weight, and this is approximately 200 times the maximal JH III level found in whole body extracts of the adult (day 4) female cockroach, Diploptera punctata (Tobe et al., 1985).

One of the objectives of the present work was to determine the distribution of JH III in the sedge $C$. iria. In order to do so, an accurate means for the extraction and subsequent determination of JH III had to be established. Presently, quantification of JH III is possible using either HPLC or a radioimmunoassay (RIA) technique that was developed to determine $\mathrm{JH}$ levels in insect haemolymph (Goodman et al., 1990, 1995). GC-MS (chemical ionisation or electron impact) may also be used to quantify JH III, but this method utilizes specialized, costly equipment and often requires extensive derivatization of the epoxide group: furthermore, the sensitivity of this method is not necessary for the analysis of plant tissue (Schooley, 1977). In the present study the RIA method has been optimized for the detection of JH III extracted from $C$. iria and compared with the HPLC method of analysis of plant tissues.

\section{EXPERIMENTAL}

\section{Plant material}

Sedges were either grown in a growth chamber at $26 \pm 2^{\circ}$ $\mathrm{C}$ under light (2800 lx) with a 16:8 light-dark cycle, or in 


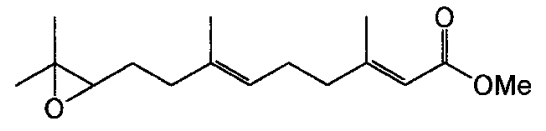

Juvenile hormone III (JH III)

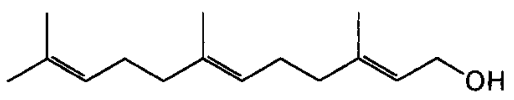

Farnesol

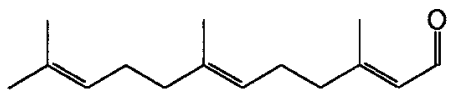

Farnesal

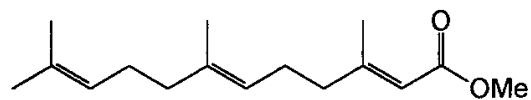

Methyl farnesoate

Figure 1. Structures of insect JH III and its biosynthetic precursors, farnesol, farnesal and methyl farnesoate.

a greenhouse from seeds obtained from Y. C. Toong (Penang, Malaysia). Voucher specimens of the following plants are available from the Royal Ontario Museum Herbarium, Canada (TRT): $C$. iria, $C$. eragrostis, $C$. polystachyos and Fimbristylis dichotoma. For experimental purposes, plants were grown in individual pots in organic potting mix (Home Gardener) and the soil was kept continuously moist by maintaining the plants in 2$5 \mathrm{~cm}$ water. Individual plants were analysed after maturity (flowering) as freshly harvested material.

\section{Extraction of plant material for HPLC analysis}

All solvents used were of HPLC grade and were purchased from Burdick and Jackson (Muskegon, MI, USA). Pre-weighed plant tissues were ground in acidwashed sand (Sigma, St. Louis, MO, USA) and liquid nitrogen, and extracted overnight in pentane at room temperature. The extract was evaporated to near dryness and subjected to column chromatography over an hydroxyapatite column (HA; BioRad, Hercules, CA, USA), to remove chlorophyll and other contaminants. The anhydrous sodium sulphate $(\mathrm{BDH}$, Toronto, ON, Canada)-HA column prepared in a Pasteur pipette was pre-washed with diethyl ether and iso-octane, followed by addition of the sample and elution with pentane:ether (70:30). The solvent was evaporated under nitrogen (Canox, Murray Hill, NJ, USA), and the sample resuspended in hexane for HPLC analysis.

\section{Extraction of plant material for radioimmunoassay}

In comparative studies between HPLC and RIA, the plant samples were prepared as for HPLC analysis. In other experiments, plant tissues were ground in liquid nitrogen, weighed and extracted with acetonitrile (HPLC grade; Burdick and Jackson) or pentane.
Acetonitrile extraction. JH III was extracted from the plant by a modification of the purification procedure for insect haemolymph (Goodman et al., 1995). Plant material $(0.1-0.4 \mathrm{~g})$ was extracted with acetonitrile $(1 \mathrm{~mL})$ at $60^{\circ} \mathrm{C}$ for $3 \mathrm{~min}$ after which samples were vortexed, centrifuged (450 $\mathrm{g}$ for $5 \mathrm{~min}$ ), the supernatant removed and the extraction of the pellet repeated. Volumes (1 mL each) of aqueous sodium chloride (4\%; Sigma) and pentane were added to the pooled acetonitrile extracts, the mixture vortexed and centrifuged ( $450 \mathrm{~g}$ for $5 \mathrm{~min}$ ) in order to separate the two phases. The pentane phase was removed and the pentane extraction repeated. The pentane phases were pooled, evaporated under a stream of nitrogen and resuspended in toluene (ACS grade; $\mathrm{BDH}$ ) for RIA analysis.

Pentane extraction. After tissue maceration, plant samples (0.1-0.4 g) were weighed and extracted overnight at room temperature with pentane $(2 \mathrm{~mL})$. Following incubation, the samples were vortexed, centrifuged (450 $\mathrm{g}$ for $5 \mathrm{~min}$ ) and the supernatant removed. Pellets were washed again with pentane, vortexed, centrifuged and the supernatants pooled. Samples were dried under a stream of nitrogen and resuspended in toluene for RIA analysis.

\section{Preparation of JHs and their biosynthetic precursors}

Farnesal was synthesized through the allylic oxidation of trans, trans-farnesol (11.4 mmol; $96 \%$ pure; Aldrich, by activated manganese dioxide $(228 \mathrm{mmol}$; Aldrich, Milwaukee, WI, USA) in the presence of anhydrous sodium carbonate $(228 \mathrm{mmol} ; \mathrm{BDH})$ and hexane $(125 \mathrm{~mL})$ according to the modified protocol of Corey et al. (1968) as described by Xiao and Prestwich (1990). The mixture was stirred for $22 \mathrm{~h}$ at $0^{\circ} \mathrm{C}$, filtered through a layer of Celite (Fisher, Fair Lawn, NJ, USA), and then concentrated in vacuo to yield the aldehyde (2.1 g; $9.53 \mathrm{mmol} ; 71.1 \%$ yield; $85 \%$ pure by $\left.{ }^{1} \mathrm{H}-\mathrm{NMR}\right)$. Farnesal was further purified by TLC on silica gel plates (Merck, Darmstadt, Germany) eluted with $10 \%$ ethyl acetate (HPLC grade; BDH) in hexane and $5 \%$ triethylamine (Sigma) after focussing in methanol (HPLC grade; Burdick and Jackson) (Sen and Garvin, 1995). The final sample $\left(R_{\mathrm{f}}=0.88\right)$ contained two major components $(31.5 \%$ and $51.6 \%)$ representing two farnesal isomers, as well as three minor components (P. Teal, USDA, Florida, USA).

Methyl farnesoate was synthesized from farnesal $(9 \mathrm{mmol})$ incubated with activated manganese dioxide (284 mmol), sodium cyanide (46.1 mmol; BDH) and glacial acetic acid $(0.76 \mathrm{~mL}$; ACS grade; $\mathrm{BDH})$ in $200 \mathrm{~mL}$ methanol (Latli and Prestwich, 1991). The mixture was stirred for $14 \mathrm{~h}$ at room temperature, filtered through Celite and then concentrated in vacuo to yield the methyl ester $(1.5 \mathrm{~g} ; 6 \mathrm{mmol} ; 53.3 \%$ yield; $80 \%$ pure by ${ }^{1}$ H-NMR). Methyl farnesoate was further purified by TLC on silica gel plates eluted with toluene: ethyl acetate:acetic acid (85:15:4) after focussing in methanol. The final sample $\left(R_{\mathrm{f}}=0.66\right)$ contained two major components $(21 \%$ and $78 \%$ ) representing two methyl farnesoate isomers (P. Teal).

JH III was extracted from the plant as detailed above and purified by HPLC. The structure was confirmed by ${ }^{1}$ H-NMR (W. G. Reynolds, Department of Chemistry, 
University of Toronto, Canada). The concentrations of stock solutions were determined from spectrophotometric measurements at $218 \mathrm{~nm}$. Tritiated JH III was synthesized through the incubation of radiolabelled methionine with the corpora allata from the Pacific beetle cockroach, Diploptera punctata, followed by purification by HPLC (Tobe and Clarke, 1985; King and Tobe, 1988). Corpora allata from day 5 mated female cockroaches were incubated in methionine-free TC 199 medium containing 2\% Ficoll (Pharmacia, Uppsala, Sweden), $1.3 \mathrm{~mm}$ calcium chloride dihydrate (Analar grade; $\mathrm{BDH}), 40 \mu \mathrm{M}$ farnesoic acid $(70 \%)$ and $\mathrm{L}-\left[{ }^{3} \mathrm{H}-\right.$ methyl]-methionine $(3.11 \mathrm{TBq} / \mathrm{mmol}$; Amersham, Little Chalfont, UK) overnight at $27^{\circ} \mathrm{C}$. The aqueous media was extracted twice with iso-octane, the pooled extracts eluted over a Seppak silica gel column (Millipore, Bedford, MA, USA) and the resulting eluent evaporated under a stream of nitrogen and resuspended in hexane prior to final purification of enantiomerically pure $\left[{ }^{3} \mathrm{H}-\right.$ methyl]-10R,11-JH III by HPLC.

\section{TLC analysis}

The preparation of samples for TLC analysis was modified from that described by Goodman et al. (1995). Bracts and inflorescence of C. iria were extracted overnight in $2 \mathrm{~mL}$ pentane at room temperature. Samples were spiked with Sudan Black B, divided into two aliquots (sample and control) and subjected to TLC according to Goodman et al. (1995). Sudan Black B gives rise to two major blue bands which, during chromatography, bracket the JH III and mark its separation from the slower migrating diglycerides and polar lipids and the faster moving triglycerides and nonpolar lipid components. The putative $\mathrm{JH}$-containing bands were scraped from the TLC plate and extracted. Samples were then analysed by RIA and an aliquot of these samples was measured spectrophotometrically at $492 \mathrm{~nm}$ in order to determine losses during chromatography. The presence of any pigments in the plant extract was corrected for by subtraction of the control from the absorbance of Sudan Black B in the samples.

\section{Hydroxyapatite and hydroxyapatite/ $\mathbf{C}_{18}$ chromatography}

Pentane extracts of plant samples were subjected to hydroxyapatite chromatography in columns prepared as described above. Following this chromatographic separation, some samples were subjected to chromatography on $\mathrm{C}_{18}$ 125A (Waters, Milford, MA, USA) in Pasteur pipette columns. These columns were washed with pentane, ether and then acetonitrile. Following application of the sample, compounds were eluted with pentane.

\section{HPLC analysis}

Plant extracts were quantified by normal-phase HPLC using a Varian (Georgetown, ON, Canada) model LC5020 chromatograph equipped with a Spheri-5 silica (Brownlee, Santa Clara, CA, USA) column $(250 \times 4.6 \mathrm{~mm}$ i.d.). The mobile phase was diethyl ether (50\% water-saturated):hexane (10:90) at a flow rate of
$1 \mathrm{~mL} /$ min. JH III was monitored at $219 \mathrm{~nm}$ using a SpectroMonitor III (SpectroMonitor, San Jose, CA, USA) and the concentration of extract calculated from the peak area by comparison with external standards. Statistical analyses were performed using the statistical package SPSS 7.5 (Chicago, IL, USA).

\section{Radioimmunoassay}

Glassware was treated following recommendations outlined in Granger and Goodman (1988); whenever possible, the use of plastic was avoided. Where noted in the below procedure, glassware was coated with polyethylene glycol (PEG, 15000-20000 MW; Sigma) to reduce JH binding (Giese et al., 1977). Microcap pipettes (Fisher) and glass syringes (Hamilton, Reno, NV, USA) were used to prepare JH III standards.

The RIA procedure was modified from Goodman et al. (1990, 1995). Antiserum was diluted in buffer A which contained $1.0 \mathrm{M}$ sodium phosphate buffer $(\mathrm{pH} 7.2$; Sigma) containing $0.1 \%$ bovine serum albumin (protease-free; Sigma), 0.1\% immunoglobin G (Sigma) and $0.02 \%$ sodium azide (Fisher). Tritiated JH III standard was prepared in buffer A in a PEG-treated vial. Both the antiserum and radiolabelled JH III standard were gently agitated for at least $30 \mathrm{~min}$ at $4^{\circ} \mathrm{C}$. Various amounts of stock JH III standard solution and the unknown samples were added to borosilicate culture tubes $(60 \times 5 \mathrm{~mm}$ i.d.; Kimble, Vineland, NJ, USA) that had been PEG-treated. The volume of each sample was adjusted to $100 \mu \mathrm{L}$ with toluene. After the solvent had been removed by lyophilisation, $1 \mu \mathrm{L}$ of ethanol (Commercial Alcohols Inc, Brampton, ON, Canada) was added to each tube and the contents vortexed mixed. Tritiated JH III stock and antiserum were added to each tube and the contents remixed by vortexing. Samples were incubated overnight at $4^{\circ} \mathrm{C}$. The assay was terminated by the addition of $100 \%$ saturated ammonium sulphate (pH 7.2; Sigma) at $4^{\circ} \mathrm{C}$. After incubation for $20 \mathrm{~min}$, the tubes were centrifuged (450 $\mathrm{g}$ for $15 \mathrm{~min}$ ), and the supernatant aspirated. Pellets were dissolved in 50\% ammonium sulphate (pH 7.2) containing $0.1 \%$ bovine serum albumin. Tubes were recentrifuged and the supernatant aspirated. The resultant pellet was dissolved in $20 \mu \mathrm{L}$ water.

Following addition of scintillation fluid and vortexing, the samples were radioassayed using a Beckman (Mississanga, ON, Canada) model LS6500 scintillation counter. The standard curve was generated by a four parameter logistic curve (Graphpad Prism, version 1.0: Graphpad Prism, San Diego, CA, USA). Concentrations of unknown samples were determined from the standard curve. Assays were performed in triplicate.

\section{Quantification of JH III in C. iria}

The amount of JH III in the plant was quantified using the optimized RIA procedure. Tissues from mature plants were divided into the roots (below-ground portion), the culm (stem), leaves, bracts (modified leaves which subtend the inflorescence), inflorescence (pedicels, peduncles and inflorescence) and nutlets (fruits). Plant material was submitted to pentane extraction as outlined above, and JH III measured by RIA. In this paper, the term level refers to the JH III content per amount of plant tissue. 
Table 1. Optimization of extraction procedures for JH III

Treatment

Acetonitrile (1.5 mL)

Acetonitrile + water $(2 \mathrm{~mL})$

Acetonitrile $+2 \%$ brine $(2 \mathrm{~mL})$

Acetonitrile $+4 \%$ brine $(2 \mathrm{~mL})$

Extraction efficiency $(\% \pm$ SD)

$8.3 \pm 1.6$

$38.4 \pm 5.3$

$33.6 \pm 0.8$

$27.1 \pm 1.5$

Acetonitrile was spiked with [ ${ }^{3} \mathrm{H}$-methyl]-JH III; triplicate samples were treated as indicated and finally extracted with pentane $(2 \times 1 \mathrm{~mL})$. The radioactivity in the resulting sample was determined and compared to the initial amount added.

\section{RESULTS AND DISCUSSION}

\section{Optimization of plant tissue extraction}

The extraction of JH III from insect haemolymph requires the use of acetonitrile and brine to disrupt the interactions between the hormone and its binding protein, followed by partitioning of JH III into pentane. However, the efficiency of extraction of JH III from $C$. iria tissues by acetonitrile was low (Table 1). In comparison, a higher yield was observed by direct extraction into pentane (Table 2). JHs are lipophilic compounds which adsorb strongly to many substrates (Giese et al., 1977): in order to determine the extent of JH III binding to plant material or glassware, $\left[{ }^{3} \mathrm{H}\right]-\mathrm{JH}$ III was added to plant tissues prior to extraction with pentane. No significant difference was observed between the control and plant tissues (Table 3), thus confirming the high efficiency of extraction of JH III from $C$. iria tissues by pentane (Tables 2 and 3). All subsequent plant extractions were performed using pentane as solvent.

\section{Comparison of chromatographic clean-up procedures}

After acetonitrile extraction, insect haemolymph samples are typically subjected to TLC in order to eliminate lipophilic compounds that interfere with the RIA (Goodman et al., 1990). For pentane extracts of JH III from plant tissues, a comparison of three clean-up procedures was made (Table 4). There was no significant difference in the measured amount of JH III in samples which were

Table 2. Optimization of extraction of JH III from plant tissues

Relative extraction efficiency $(\% \pm \mathrm{SD})$

Pentane

$100 \pm 15.2$

Acetonitrile

$60.6 \pm 12.3$

C. iria tissues (bracts and inflorescence) were ground in liquid nitrogen and extracted with either pentane $(2 \times 1 \mathrm{~mL})$ or acetonitrile $(2 \times 1 \mathrm{~mL}): 1 \mathrm{~mL}$ of brine $(4 \%$ sodium chloride) was added to the acetonitrile supernatant and the mixture extracted with pentane $(2 \times 1 \mathrm{~mL})$. Triplicate samples were subject to TLC and appropriate bands extracted and analysed by RIA with antiserum 31867 $(1: 2000)$ and $\left[{ }^{3} \mathrm{H}\right.$-methyl]-10R-JH III. Paired $t$-tests (one tail, $\rho=0.049$ ) demonstrated that there is a significant difference between the extraction efficiency of these two solvents.
Table 3. Efficiency of extraction of JH III from plant samples using pentane

Plant tissue

Extraction efficiency $(\% \pm S D)$

Control

$100 \pm 1.9$

Bracts

$92.7 \pm 7.4$

Inflorescence

$87.0 \pm 7.2$

Roots

$100.1 \pm 2.9$

Culm

$97.7 \pm 24.6$

Tritiated JH III was added to triplicate plant samples which were then extracted in pentane $(2 \times 1 \mathrm{~mL})$. No significant differences were observed in the extraction efficiencies between the control and the plant tissues (one factor ANOVA, $\rho=0.636$ ); blank samples (plant tissues incubated without the radiolabelled ligand) contained less than 25 dpm per sample.

directly extracted in pentane or those which had undergone TLC. A decrease in JH III amount was observed in samples which had been subjected to hydroxyapatite and hydroxyapatite/ $\mathrm{C}_{18}$ chromatography compared with controls. However, Sudan Black B was used as an internal control during TLC allowing for the correction of losses during this procedure, but no internal standard for the column chromatographic procedures was used. Therefore, observed differences in JH III between the pentane control and samples subjected to these further chromatographic procedures reflect slight losses during manipulations. In subsequent experiments, pentane extracts of the plant tissue were used directly for analysis by RIA.

\section{Comparison of related plant species}

Plant material may interfere with the RIA through the binding of the antiserum or JH III to plant compounds such as lignins and tannins or through cross-reactivity of the antiserum to compounds other than JH III. In order to determine the extent of these non-specific interactions, three related plant species were tested, namely, Cyperus eragrostis and $C$. polystachyos (of the same genus as $C$. iria) and Fimbristylis dichotoma (which belongs to the same subfamily, Cyperoideae). JH was not detected in extracts of these plants thus permitting their use in the determination of the amount of plant material that would cross-react with the RIA. The results indicate that

Table 4. Comparison of efficiency of the purification procedures employed

Method

Relative extraction efficiency $(\% \pm \mathrm{SD})$

Pentane extraction

Pentane extraction/TLC

Pentane extraction/HA

Pentane extraction/HA/C 18

$100 \pm 33.1$

$87.1 \pm 30.9$

$75.2 \pm 36.4$

$81.2 \pm 19.8$

C. iria tissues (bracts and inflorescence) were ground in liquid nitrogen, extracted with pentane $(2 \times 1 \mathrm{~mL})$ and either analysed directly or subjected to clean-up chromatographic procedures such as TLC, hydroxyapatite (HA) chromatography or reversed-phase chromatography $\left(\mathrm{C}_{18}\right)$ prior to analysis; triplicate samples were analysed by RIA with antiserum 31867 (1:2000) and [ ${ }^{3} \mathrm{H}$-methyl]-10R-JH III. No significant differences were observed in the extraction efficiencies between the methods (one factor ANOVA, $\rho=0.706$ ). 


\begin{tabular}{|c|c|}
\hline \multicolumn{2}{|c|}{$\begin{array}{l}\text { Table 5. Radioimmunoassay cross-reactivities of closely } \\
\text { related plants }\end{array}$} \\
\hline Plant & Cross-reactivity observed at: \\
\hline $\begin{array}{l}\text { Fimbristylis dichotama } \\
\text { Cyperus polystachyos }\end{array}$ & $\begin{array}{l}>20 \mathrm{mg} \text { of plant tissue } \\
\text { None detected (at } \\
\text { concentrations up to } 200 \mathrm{mg} \text { ) }\end{array}$ \\
\hline Cyperus eragrostis & $>150 \mathrm{mg}$ \\
\hline \multicolumn{2}{|l|}{ Plant + JH III } \\
\hline $\begin{array}{l}\text { Fimbristylis dichotama } \\
\text { Cyperus eragrostis }\end{array}$ & $\begin{array}{l}>25 \mathrm{mg} \text { (interferes with RIA) } \\
>25 \mathrm{mg} \text { (interferes with RIA) }\end{array}$ \\
\hline \multicolumn{2}{|c|}{$\begin{array}{l}\text { Cross-reactivities of extracts of three plant species related } \\
\text { to C. iria were compared by RIA using antiserum } 31867 \\
(1: 1750) \text { and }\left[{ }^{3} \mathrm{H}-\text { methyl]-10R-JH III as the radiotracer. In the }\right. \\
\text { second experiment, pentane extracts were spiked with } \\
500 \text { pg of JH III and analysed by RIA. }\end{array}$} \\
\hline
\end{tabular}

amounts greater than $20 \mathrm{mg}$ of plant tissue could interfere with the assay (Table 5). In the second experiment, tissue extracts were spiked with JH III and analysed. Here, it was observed that amounts greater than $25 \mathrm{mg}$ of material interfered with the RIA, preventing the detection of JH III. Therefore, in all subsequent experiments with $C$. iria, less than $10 \mathrm{mg}$ of tissue was assayed.

\section{Cross-reactivity of the biosynthetic precursors of JH III}

In the corpora allata of the cockroach $D$. punctata, the biosynthesis of JH III from farnesyl diphosphate occurs through five enzymatic steps (Cusson et al., 1991). The competitive displacement curves of three of these biosynthetic intermediates, farnesol, farnesal and methyl farnesoate, with the antiserum 31867 demonstrated that the antiserum has little affinity for these compounds (Fig. $2)$; the $\mathrm{ED}_{50}$ values of these compounds relative to JH III indicate that the antiserum has over a 2000-fold higher affinity for JH III than for the biosynthetic precursors tested (Table 6).

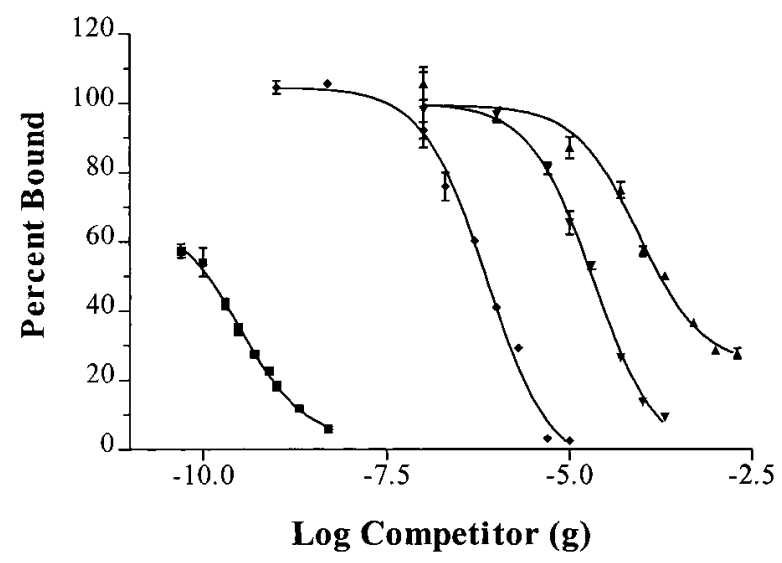

Figure 2. Competitive displacement curves for the biosynthetic precursors of JH III, namely farnesol, farnesal and methyl farnesoate. The cross-reactivities of farnesol ( $-\square-)$, farnesal $(--)$ and methyl farnesoate $(-\boldsymbol{\Delta}-)$ with the antiserum 31867 (1:1750), compared with JH III (- - - -), were determined by RIA using $\left[{ }^{3} \mathrm{H}\right.$-methyl]-10R-JH III. Each point represents the mean \pm the standard deviation of triplicate experiments.
Table 6. Summary of displacement values for JH III and its biosynthetic precursors

$\begin{array}{lc}\text { Compound } & \mathrm{ED}_{50}(\mathrm{ng})^{\mathrm{a}} \\ 10 R-\mathrm{JH} \text { III } & 0.323 \\ \text { Farnesol } & 89590 \\ \text { Farnesal } & 21290 \\ \text { Methyl farnesoate } & 735\end{array}$

a Dose of competitor compound required to displace $50 \%$ of the radiotracer $\left[{ }^{3} \mathrm{H}\right.$-methyl]-10R-JH III.

\section{Comparison of HPLC and RIA methods for the analysis of JH III in tissues of $C$. iria tissues}

Standards of JH III and extracts of plant tissue were analysed by HPLC and RIA [Fig. 3(A, B)]. No significant differences in JH III levels were observed using these two techniques, confirming that they can be used interchangeably with confidence. The RIA technique has a higher sensitivity for JH III than HPLC; antiserum 31867 displays an $\mathrm{ED}_{50}$ in the range of $323 \mathrm{pg}$ against $10 \mathrm{R}-\mathrm{JH}$ III, using [ $\left.{ }^{3} \mathrm{H}\right]-\mathrm{JH}$ III as the radiotracer (Table 6), whereas the detection limit of HPLC is in the ng range. Therefore,
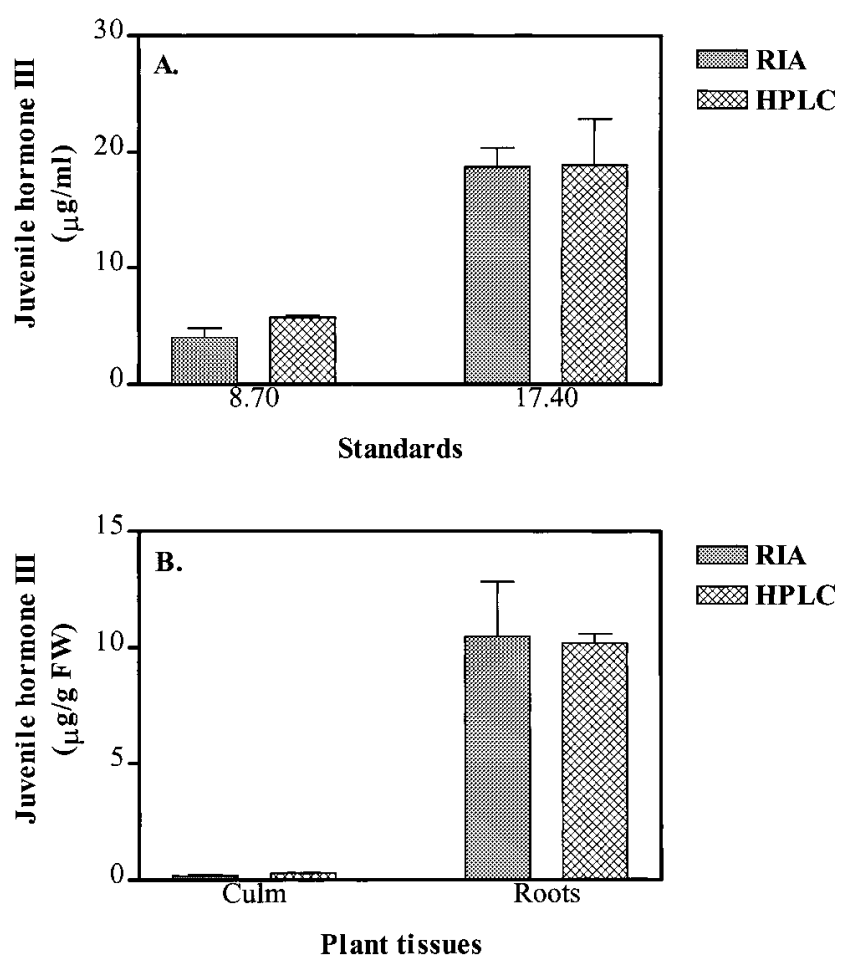

Figure 3. Comparison of HPLC and RIA. (A) JH III standards $(8.7 \mu \mathrm{g} / \mathrm{mL}$ and $17.4 \mu \mathrm{g} / \mathrm{mL})$ were analysed in triplicate by HPLC and RIA (bars represent means \pm standard deviation). The results were compared by a paired $t$-test followed by a sequential Bonferroni test; no significant difference was found between these two techniques [two tail, $\rho=0.084$ (8.7), $\rho=0.964$ (17.4)]. (B) Extracts of $C$. iria tissues (culm and root) were assayed in triplicate by HPLC (as outlined in the Experimental section) and also by RIA (with antiserum 31867 $(1: 1500)]$ and using $\left[{ }^{3} \mathrm{H}\right.$-methyl]-10R-JH III which had been optimized for plant tissues (bars represent means \pm standard deviation). Results were compared by a paired $t$-test followed by a sequential Bonferroni test; no significant difference was observed between these two techniques [two tail, $\rho=0.034$ (culm), $\rho=0.823$ (roots)]. 

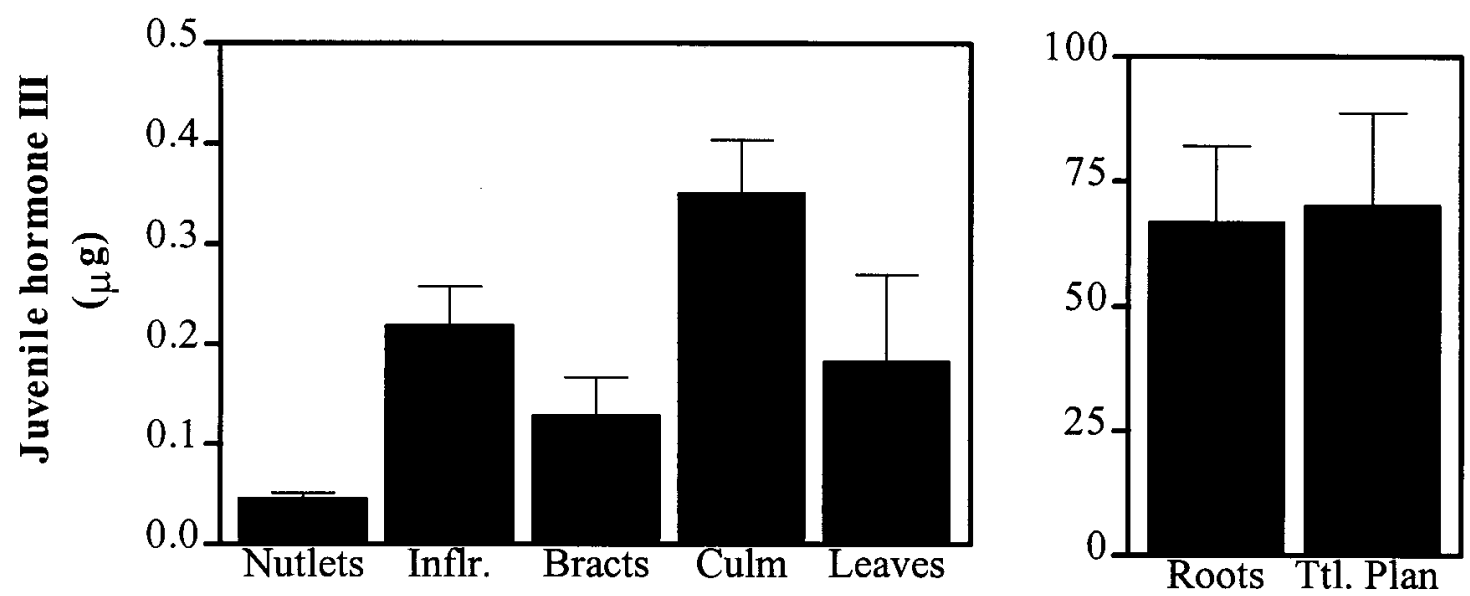

\section{Plant Tissue}

Figure 4. Distribution of juvenile hormone III in Cyperus iria plants. JH III in the tissues of mature plants was measured by RIA with antiserum 31867 (1:2000) using $\left[{ }^{3} \mathrm{H}\right.$-methyl]-10R-JH III as the radiotracer. Plant tissues were divided into the nutlets $(n=6)$, inflorescence (Inflr., pedicels, peduncles and inflorescence, $n=6)$, bracts $(n=6)$, culm (stem, $n=5)$, leaves $(n=5)$ and roots $(n=6)$. The total amount of $\mathrm{JH}$ III in the plant (Ttl. Plan) was also determined $(n=5)$ (bars represent means \pm standard error).

the RIA allows determination of JH III in as little as $10 \mathrm{mg}$ of plant material.

\section{Distribution of JH III in mature plants of $C$. iria}

Sites of accumulation of JH III in $C$. iria were determined using the optimized RIA (Fig. 4). Levels in the aboveground tissues ranged from 0.2 to $1.2 \mu \mathrm{g} / \mathrm{g}$ fresh weight, whereas in the root tissue the average level was $43.5 \mu \mathrm{g} /$ $\mathrm{g}$, representing over $90 \%$ of the total JH III in the plant. These levels are approximately 3.5-fold less than those previously reported (Toong et al., 1988). There is also a 6 -fold difference between the level of JH III detected in these whole plant extracts and those reported from leaf extracts of 2-month-old plants of C. iria (Schwartz et al., 1998). These discrepancies are attributed to changes in JH III levels in the plant throughout development and to differences in cultivars and environmental conditions under which the plants were grown.

These results demonstrate that the amount of JH III in $C$. iria can be determined by HPLC or RIA and that there is good correlation between these two assay techniques [Fig. 3(A, B)]. The RIA was developed for the analysis of JH III titres in insect haemolymph where it is necessary to extract the compound into acetonitrile, partition into pentane and then separate this compound from the interfering lipids using TLC (Goodman et al., 1995). In C. iria, direct extraction of JH III from plant tissues with pentane was more efficient than with acetonitrile (Table 2) and subsequent clean-up of the extracts was unnecessary because of the lower lipid content (Table 4). Cross-reactivity of the antiserum with biosynthetic precursors of JH III (insects) or extracts from closely related plants species was not significant (Fig. 2, Tables 5 and 6). However, these results did indicate that analyses employing concentrated plant extracts $(>25 \mathrm{mg} / \mathrm{mL}$ toluene) interfered with the RIA (Table 5).

The advantage of RIA over HPLC is its increased sensitivity which permits detection of pg amounts of $\mathrm{JH}$ III, allowing accurate determinations of the $\mathrm{JH}$ in ca. $10 \mathrm{mg}$ amounts of plant tissue. In the distribution profile of above-ground tissues, the highest amounts of JH III were localized in the leaves, inflorescence and culm (Fig. 4); however, the vast majority of JH III was detected in the roots. This suggests that the roots may be the site of biosynthesis, although it is fully possible that JH III is synthesized in the leafy tissues and transported to the root tissue for storage.

Although JH III has only been isolated from C. iria and C. aromaticus (Toong et al., 1988), structurally similar compounds have been isolated from the roots of $C$. iria and related Cyperus species (Iwamura et al., 1978b,c, 1979; Iwamura, 1979; Komai et al., 1981). For example, methyl farnesoate, the biosynthetic precursor of JH III in insects, has been isolated from C. iria, C. monophyllus, C. pilosus and C. serotinus (Iwamura et al., 1978a,c, 1979; Komai et al., 1981; Toong et al., 1988), as well as from grape skins (Versini et al., 1994) and the bark of Polyalthia viridis Craib (Kijjoa et al., 1990). Other structurally related linear sesquiterpenoids have been isolated from $C$. microiria (Iwamura et al., 1978b) and $C$. polystachyos (Iwamura, 1979). This suggests that JH III, methyl farnesoate and other similar compounds may be present in a diverse array of plant species. However, in this, and another study (Schwartz et al., 1998), JH III was not detected by RIA in the following plant species $-C$. albostriatus, C. alternifolius, C. eragrostis, C. esculentus, C. miliifolius, C. papyrus, C. polystachyos and Fimbristylis dichotama.

The relatively high levels of JH III in the plant suggests that this compound plays an important role(s) in C. iria. At present, its biological relevance is speculative (Bede et al., 1998; Bede and Tobe, 1999), but possibilities include plant-insect, plant-plant and plant-nematode interactions. There are a few reports where $C$. iria has been shown to interfere with insect development and these effects may be attributable to JH III (Toong et al., 1988; Meneses and de la Osa, 1988; Schwartz et al., 1998). However other reports indicated that some insect species were able to feed on the plant without adverse effects (Naresh and Smith, 1984; Dela Cruz, 1986). These may be examples of insect species which are able to avoid plant tissues rich in JH III or to metabolize any 
ingested compound. JH III may also function to reduce plant competition by inhibiting the germination and growth of plants in the immediate vicinity. Two of the biosynthetic precursors of JH III, methyl farnesoate and farnesol, have demonstrated potent allelopathic activity (Komai et al., 1981; Wardle and Short, 1982) which may, in part, explain the invasive nature of $C$. iria (Holm et al., 1977). JH III may also serve to protect the plant against phytoparasitic nematodes. $\mathrm{JH}$, or biosynthetic precursors, have been used to arrest the development of nematodes (Meerovitch, 1965; Rogers, 1978; Glassburg et al., 1983; Davey, 1988). However, an effect on plant parasitic nematodes has not yet been demonstrated (Johnson and Viglierchio, 1970; Rogers, 1978).

\section{Acknowledgements}

We are grateful to W. G. Reynolds (Department of Chemistry, University of Toronto) and P. Teal (USDA, Florida) for the chemical analysis of standards, F. C. Baker (Zoecon, Corp., Palo Alto, CA, USA) for the generous gift of farnesoic acid, E. Blumwald (Department of Botany, University of Toronto) for use of the spectrophotometer, L. Rowe (Department of Zoology, University of Toronto) for advice on statistics, Connie Sokos (Department of Botany, University of Toronto) for the sedges $C$. eragrostis, $C$. polystachyos and $F$ dichotoma, and J. R. Zhang (Department of Zoology, University of Toronto) for performing the corpora allata dissections. We also thank $\mathrm{J}$. Edwards (Central Science Laboratory, MAFF, San Hutton, Yorks, UK) for critical reading of this manuscript and insightful comments. This research was supported by grants from the National Science and Engineering Research Council of Canada (SST).

\section{REFERENCES}

Bede, J. C. and Tobe, S. S. (1999). Insect juvenile hormones in plants. In Studies in Natural Products Chemistry. (Rahman, A.-U., ed.), Vol. 24, 369-418. Elsevier, Amsterdam.

Bede, J. C., Goodman, W. G. and Tobe, S. S. (1998). Insect juvenile hormone III in the sedge, Cyperus iria L.: Distribution and possible biological significance. Pure Appl. Chem. www.iupac.org/symposia/proceedings/ phulat97/bede.html pp. 1-9.

Corey, E. J., Gilman, N. W. and Ganem, B. E. (1968). New methods of the oxidation of aldehydes to carboxylic acids and esters. J. Am. Chem. Soc. 90, 5616-5617.

Cusson, M., Yagi, K. J., Ding, Q., Duve, H., Thorpe, A., McNeil, J. N. and Tobe, S. S. (1991). Biosynthesis and release of juvenile hormone and its precursors in insects and crustaceans: the search for a unifying arthropod endocrinology. Insect Biochem. 21, 1-6.

Davey, K. G. (1988).Endocrinology of nematodes. In Endocrinology of Selected Invertebrate Types. (Laufer, $\mathrm{H}$. and Downer, R. G. H., eds.), pp. 63-86. Alan R. Liss, New York.

Dela Cruz, C. G. (1986). Host plant range of the planthopper, Nisia atrovenosa. Int. Rice Res. Newslett. 11, 26-27. [CABS 074-04038.]

Giese, Ch., Spindler, K. D. and Emmerich, H. Z. (1977). The solubility of insect juvenile hormone in aqueous solutions and its adsorption by glassware and plastics. $Z$. Naturforsch. 32c, 158-160.

Gilbert, L. I., Rybczynski, R. and Tobe, S. S. (1996). Endocrine cascade in insect metamorphosis. In Metamorphosis. (Gilbert, L. I., Tata, J. R. and Atkinson, B. G., eds.), pp. 59107. Academic Press, New York.

Glassburg, G. H., Tefft, P. M. and Bone, L. W. (1983). Juvenoid effects on Nippostrongylus brasiliensis and Heterodera glycines (Nematoda). Proc. Helminthol. Soc. Wash. 50, 62-68.

Goodman, W. G., Coy, D. C., Baker, F. C., Lei, X. and Toong, Y. C. (1990). Development and application of a radioimmunoassay for the juvenile hormones. Insect Biochem. 20, 357-364.

Goodman, W. G., Orth, A. P., Toong, Y. C., Ebersohl, R., Hiruma, K. and Granger, N. A. (1995). Recent advances in radioimmunoassay technology for the juvenile hormones. Arch. Insect Biochem. Biophys. 30, 295-306.

Granger, N. A. and Goodman, W. G. (1988). Radioimmunoassay: juvenile hormones. In Immunological Techniques in Insect Biology. (Gilbert, L. I. and Miller, T. A., eds.), pp. 215-251. Springer London.

Holm, L. G., Plucknett, D. L., Pancho, J. V. and Herberger, J. P. (1977). Cyperus iria L. In The World's Worst Weeds. pp. 240-242. University Press of Hawaii, Honolulu.

Iwamura, J. (1979). The constituents of essential oils from Cyperus polystachyos Rottb., Cyperus globosus allioni and Cyperus difformis L. Nippon Nogei Kagaku Kaishi 53, 343-347. [Chem. Abstr. 92, 116232f.]

Iwamura, J., Kameda, M., Komai, K. and Hirao, N. (1978a). Studies on the constituents in Cyperaceae. III. The constituents of essential oil from Cyperus iria L. Nippon Nogei Kagaku Kaishi 52, 379-383.

Iwamura, J., Kameda, M., Komai, K. and Hirao, N. (1978b). Studies on the constituents of Cyperaceae. II. The constituents of the essential oil from Cyperus microiria Steud. Nippon Kagaku Kaishi 1552-1555. [Chem. Abstr. 90, 69086h.]

Iwamura, J., Komaki, K., Komai, K. and Hirao, N. (1978c). Studies on constituents in Cyperaceae. V. The constituents of essential oil from Cyperus monophyllus Vahl. Nippon Nogei Kagaku Kaishi 52, 516-515. [Chem. Abstr. 90, 135072d.]

Iwamura, J., Komaki, K., Komai, K. and Hirao, N. (1979). Studies on constituents in Cyperaceae. IV. The constituents of essential oil from Cyperus pilosus Vahl. Nippon Kagaku Kaishi 255-258. [Chem. Abstr. 90, 164723x.]

Johnson, R. N. and Viglierchio, D. R. (1970). Heterodera schachtii responses to exogenous hormones. Exp. Parasitol. 27, 301-309.

Kijjoa, A., Pinto, M. M. M., Pinho, P. M. M., Tantisewie, B. and Herz, W. (1990). Clerodane derivatives from Polyalthia viridis. Phytochemistry 29, 653-655.

King, L. E. and Tobe, S. S. (1988). The identification of an enantioselective $\mathrm{JH}$ III binding protein from the haemolymph of the cockroach, Diploptera punctata. Insect Biochem. 18, 793-805.

Komai, K., Sugiquaka, Y. and Sato, S. (1981). Plant-growth retardant of extracts obtained from water nutgrass (Cyperus serotinus Rottb.). Kinki Daigaku Nogakubu Kiyo 14, 57-65. [Chem. Abstr. 95, 162961c.]

Latli, B. and Prestwich, G. D. (1991). Synthesis of labelled (10R)-juvenile hormone III bisepoxide, and its photoaffinity analogue, $\left[12-{ }^{3} \mathrm{H}\right]-(10 R)-6,7,10,11$-bisepoxyfarnesyl diazoacetate (BEFDA). J. Labelled Comp. Radiopharm. 29, 1168-1173.

Meerovitch, E. (1965). Studies on the in vitro axenic development of Trichinella spiralis. Can. J. Zool. 43, 8185.

Meneses, C. R. and G. de la Osa, J. (1988). Principal weed hosts of Hydrellia sp. in the southern rice-growing zone of Sancti Spiritus, Cuba. Rev. Agr. Ent. 15, 90-92. [CABS 07910772.]

Naresh, J. S. and Smith, C. M. (1984). Feeding preference of the rice stink bug on annual grasses and sedges. Entomol. Exp. Applic. 35, 89-92.

Rogers, W. P. (1978). The inhibitory action of insect juvenile hormone on the hatching of nematode eggs. Comp. Biochem. Physiol. 61A, 187-190.

Rosenthal, G. A. and Berenbaum, M. R. (eds.) (1991). Herbivores: Their Interactions with Secondary Plant Metabolites. Vol. 1. The Chemical Participants. Academic Press, Toronto.

Schooley, D. A. (1977). Analysis of the naturally occurring juvenile hormones - their isolation, identification, and titre determination at physiological levels. In Analytical 
Biochemistry of Insects. (Turner, R. B., ed.), pp. 241-287. Elsevier, Amsterdam.

Schwartz, A. M., Paskewitz, S. M., Orth, A. P., Tesch, M. J. Toong, Y. C. and Goodman, W. G. (1998). The lethal effects of Cyperus iria on Aedes aegypti. J. Am. Mosquito Control Assoc. 14, 78-82.

Sen, S. E. and Garvin, G. M. (1995). Substrate requirements for lepidopteran farnesol dehydrogenase. J. Agric. Food Chem. 43, 820-825.

Tobe, S. S. and Clarke, N. (1985). The effect of L-methionine concentration on juvenile hormone biosynthesis by the corpora allata of the cockroach Diploptera punctata. Insect Biochem. 15, 175-179.

Tobe, S. S. and Feyereisen, R. (1983). Juvenile hormone biosynthesis: regulation and assay. In Endocrinology of Insects. (Downer, R. G. H. and Laufer, H., eds.), pp. 161178. A. R. Liss, New York.

Tobe, S. S., Ruegg, R. P., Stay, B. A., Baker, F. C., Miller, C. A. and Schooley, D. A. (1985). Juvenile hormone titre and regulation in the cockroach Diploptera punctata. Experientia 41, 1028-1034.

Toong, Y. C., Schooley, D. A. and Baker, F. C. (1988). Isolation of insect juvenile hormone III from a plant. Nature 333, 170-171.

Versini, G., Rapp, A., Dalla Serra, A., Pichler, U. and Ramponi, M. (1994). Methyl trans-geranate and farnesoate as markers for Gewürztraminer grape skins and related distillates. Vitis 33, 139-142.

Wardle, K. and Short, K. C. (1982). Effects of isoprenoid alcohols and fatty acids on root elongation, germination and their association with stomatal activity. Biochem. Physiol. Pflanzen 177, 210-215.

Wigglesworth, V. B. (1985). Historical perspectives. In Comprehensive Insect Physiology, Biochemistry and Pharmacology. Vol. 7. (Kerkut, G. A. and Gilbert, L. I., eds.), pp. 1-24. Pergamon Press, New York.

Xiao, X-Y. and Prestwich, G. D. (1990). Minimising geometric isomerisation during oxidation of allylic alcohols to aldehydes. Synth. Comm. 20, 3125-3130. 